\section{Reformas del sector de la salud en la Región de las Américas}

\author{
El Comité Editorial
}

El presente número especial de la Revista Panamericana de Salud Pública/Pan American Journal of Public Health está destinado a ofrecer a los lectores un análisis actualizado sobre el pasado reciente y el presente de las reformas del sector de la salud en la Región de las Américas, así como una prospectiva sobre su futuro. El número forma parte del esfuerzo que desde comienzos de los años noventa viene desarrollando la Organización Panamericana de la Salud/Organización Mundial de la Salud (OPS/OMS) para poner a disposición de los países una mayor cantidad de información, experiencias de interés, lineamientos de política e instrumentos útiles para el diseño y la adopción de estrategias y acciones destinadas a introducir cambios sustantivos en el sector de la salud.

La I Cumbre de las Américas (1994) le dio a la OPS el mandato de seguir el desarrollo y evaluar los resultados de las reformas del sector de la salud en la Región de las Américas. Conjuntamente con el Banco Mundial y el Banco Interamericano de Desarrollo, la OPS/OMS organizó en 1995 la Reunión Especial sobre Reforma del Sector de la Salud e intensificó sus acciones de cooperación en este campo. En 1997, la OPS/OMS difundió un documento de posición ante los procesos de reforma del sector y ese mismo año se lanzó la iniciativa conjunta entre la Agencia de los Estados Unidos para el Desarrollo Internacional, la OPS/OMS y otros socios sobre la reforma del sector en América Latina y el Caribe. Esta iniciativa tiene como objetivo apoyar procesos de reforma que fomenten el acceso equitativo a servicios de salud más eficaces y se ha ido transformando a lo largo de los últimos tres años en un referente valioso para los actores relevantes en este campo.

Este número especial se ha organizado en tres grandes secciones. La primera, dedicada a "El pasado y el presente de las reformas", describe el contexto, la situación y las tendencias de las reformas, y analiza en profundidad la mayoría de los temas que han sido (y, en gran medida, siguen siendo) críticos en las agendas de cambio durante la década de los noventa.

La segunda, titulada "El futuro de las reformas", propone interrogantes y trata de explorar los nuevos retos que se anuncian en este campo en los albores de un nuevo milenio. Constituyen ejemplos las relaciones entre la seguridad social y los sistemas de salud y los desafíos derivados de hacer frente a la exclusión en salud, de fortalecer la práctica de la salud pública, de reorientar los sistemas y servicios con un enfoque de promoción o de concebir y armonizar la cooperación internacional en este ámbito bajo una nueva óptica.

La tercera sección, "Hacia una nueva generación de reformas", contiene un artículo donde se examinan las lecciones derivadas de las reformas del sector de la salud emprendidas desde finales de los años ochenta y los temas críticos que habrá que abordar en los próximos años.

Las tres secciones se complementan con una serie de "Casos de países" que presentan experiencias de reforma del sector de la salud en uno o varios campos temáticos. Estos ejemplos han sido encargados a personas con responsabilidades políticas en el sector o a profesionales con larga trayectoria y prestigio en su país.

Este número especial ha sido un reto que el Comité Editorial afrontó con ilusión y empeño. Quisimos abrir un espacio donde pudieran expresarse múltiples voces procedentes de ámbitos tan variados como la política, el gremio académico, la gestión de los sistemas y servicios y los organismos de cooperación internacional. Ello nos obligó a leer, a reflexionar y a intercambiar opiniones; nos mostró cuán complejo y dinámico es el tema de las reformas del sector de la salud y cuán relativo el conocimiento sobre él; pero, sobre todo, nos motivó a seguir trabajando en pro de la salud de los pueblos de América y de sistemas de salud más solidarios, útiles y sostenibles, y nos sugirió ideas y modos de seguir intentándolo.

Confiamos en que los lectores, como nosotros, consideren que el resultado conseguido mereció el esfuerzo. 